\title{
Bio-oil blended butanol as a fuel to the spark ignition internal combustion reciprocating engine
}

\begin{abstract}
The article presents results on combustion of the bio-oil blended butanol in the spark ignition engine. Bio-oil is a mixture of hydrocarbons condensing to liquified phase while cooling it down to ambient temperature. In general, the liquid called bio-oil is a byproduct of the pyrolysis process of organic matter. Results from analysis presented in the manuscript include the following: in-cylinder pressure traces and toxic exhaust emissions. Finally, comparison of these results with results from combustion of n-butanol reference fuel were provided. Obtained results indicate satisfactory, eco-friendly possibility for utilization of bio-oil in the internal combustion engine
\end{abstract}

Key words: bio-oil, pyrolysis, butanol, IC engine

\section{Introduction}

Pyrolytic bio-oil is a mixture of hydrocarbons that arises as a result of the thermal processing of organic matter in the pyrolysis. During pyrolysis the substrate is heated to a temperature in the range $300-1000^{\circ} \mathrm{C}$ the absence of oxygen, the process is endothermic. Depending on the temperature, pressure, heating rate and the particle size of the parts, is obtained the various proportions of products in the form of: gases, liquids, solids. For low temperatures $300-450^{\circ} \mathrm{C}$ and longtime of the material in the reactor 600-6000s the largest share of the pyrolysis products are solids. In the medium temperature range (from $450-700^{\circ} \mathrm{C}$ ) and a range time of from 1 to 5 seconds, most liquid products formed, and the maximum temperature $\left(700-1000^{\circ} \mathrm{C}\right)$ and the shortest time less than 1 second are gaseous products. For the production of bio-oil by pyrolysis is used the middle range temperature as the most efficient. In other article, research into the production of bio-oil from pyrolysis of waste was carried out using: the worn out tires, plastics waste, fruit, fish waste, etc. [6, 8].

According to the authors in the world it is 29 million tons of tires recyclable, and only 6.6 million tonnes will be processed. The remaining waste is not processed due to the lack of cost-effective method. In the study, they carried out the pyrolysis of used tires, cut into pieces measuring about $10 \times 10 \mathrm{~cm}$, at a temperature of $450-500^{\circ} \mathrm{C}$ over a period of 8 hours. As a result of thermal decomposition of tires are: oil pyrolysis, pyrolysis gas, charred residue and steel wire. The pyrolysis bio-oil was distilled at three temperatures of $160^{\circ} \mathrm{C}$, $204^{\circ} \mathrm{C}$ and $350^{\circ} \mathrm{C}$. The most received medium fraction. Then, they compared the characteristics of the bio-oil and diesel parameters. The results were as follows: characterized pyrolysis oil is more viscous, which amounted to $2.12 \mathrm{~mm}^{2} / \mathrm{s}$, than diesel oil $\left(3.54 \mathrm{~mm}^{2} / \mathrm{s}\right)$. The distillation fractions were characterized by a lower viscosity, which ranged from 1.18 $\mathrm{mm}^{2} / \mathrm{s}$ fraction light to $1.36 \mathrm{~mm}^{2} / \mathrm{s}$ for fraction hard. The density of the pyrolysis oil was higher than $860 \mathrm{~kg} / \mathrm{m}^{3}$. Diesel oil fulfill the requirements of DIN EN 590 in the density range of the diesel fuel, which should not exceed $860 \mathrm{~kg} / \mathrm{m}^{3}$. Fractions of the distillation are a density of $825 \mathrm{~kg} / \mathrm{m}^{3}$ to 885 $\mathrm{kg} / \mathrm{m}^{3}$. Only light fraction fulfilled the requirement of the standard. Another parameter which is significant in terms of suitability of the fuel is the acid number. For commercial diesel oil amounted to less than $0.08 \mathrm{mg} \mathrm{KOH} / \mathrm{g}$, and the pyrolysis oil $4.33 \mathrm{mg} \mathrm{KOH} / \mathrm{g}$, a distillation fraction of bio-oil for this parameter was in the range $2.45-3.77 \mathrm{mg} \mathrm{KOH} / \mathrm{g}$. The standard allows the acid number of no greater than 0.5 $\mathrm{mg} \mathrm{KOH} / \mathrm{g}$ of oil, therefore, only diesel to meet this criterion. The next parameter comparable was the flash point for oil amounted to less than $55^{\circ} \mathrm{C}$ and fulfilled the requirements of the standard. Pyrolytic bio-oil also met this criterion and the ignition temperature was $53^{\circ} \mathrm{C}$, and the fractions lit up at $5.5^{\circ} \mathrm{C}$ light fractions to $40^{\circ} \mathrm{C}$ heavy fractions. Based on the study, the authors found that the separated fractions of pyrolysis oil can not constitute an independent fuel, because they do not meet the standard requirements [12].

Other scientists have conducted studies on the pyrolysis oven, where the heat source is microwave, but Beneroso D., T. Monti, E.T. Kostas and J. Robisnos critically assessed the microwave pyrolysis process. They emphasize that the experiments in the laboratory scale will never be implemented in the industry, because there is no microwave source with adequate power and which will be worked continuously. And the second problem is to transfer energy from the electromagnetic wave to the material batch, which is not always efficient [2].

In Ghana, looking for alternative ways of obtaining fuel in order to become independent of fossil fuels. Potential see in the peel of oranges as a substrate for the production of biooil by pyrolysis. With the increase in demand for processed oranges and orange while increasing crop to 1.6 million hectares in the coming years they could replace $6.7 \%$ of all fuels, both diesel and gasoline to bio-fuel in the processing of $10 \%$ of waste from oranges. The authors pay more attention to one fact that bio-oil rather be used as a fuel additive and not as a stand-alone fuel. With the support of sector fruit processing by governments and increasing the production orange waste, production bio-oil from peel orange is the most real [1].

Successive authors see potential in waste from the fishing industry. In 2008, fish production reached 144 million tons, half of which is waste. The waste from the fish oil content ranges from $40-65 \%$. Currently, the removal of fish 
waste is costly in terms of both economic and ecological. The authors presented the properties of fish oil (waste from salmon). Moreover, they attempted mixed with pyrolysis oil produced from softwood sawdust. The experiment showed that the mixture separate after several minutes, a slight improvement of the miscibility of adding methanol [6].

Other ecological aspect which provide decrease in emission of exhaust gases is use of alcohol fuel in an engine. Using an alcohol in an CI engine is difficult because of its properties which not allow to ignite it as a single fuel. Use a hydrocarbon-alcohol blends in $\mathrm{CI}$ engine cause decrease in $\mathrm{CO}_{2}$ and soot emissions what is discussed by Tutak et al. [9-11].

In the literature a studies can be found, were pyrolysis oil was successfully used to supply a diesel engine. The paper presents the results of the experiment on combustion of mixture pyrolysis bio-oil with alcohols in spark ignition engine $[5,13]$.

\section{Description of the research stand}

The test bed consists of the following:

- Single cylinder engine with variable compression ratio (b=85 mm; $\left.\mathrm{s}=115 \mathrm{~mm} ; \mathrm{V}=650 \mathrm{~cm}^{3} ; \varepsilon=6-14\right)$,

- Port fueled system for both gaseous and liquid fuels with heaters for warming up fuels (Fig. 1,2),

- Dynanometer with breaking power of $5.5 \mathrm{~kW}$,

- Electronic engine control system for spark timing and fuel control,

- Signal gas analysers,

- Data acquisition system with A/D converter resolution of 16 bits and sampling frequency of $100 \mathrm{kHz}$ per each channel,

- Primary fuel applied to investigation was n-butanol due to satisfactory dilution rate of bio-oil in it.

The test stand outline is presented in Fig. 3.

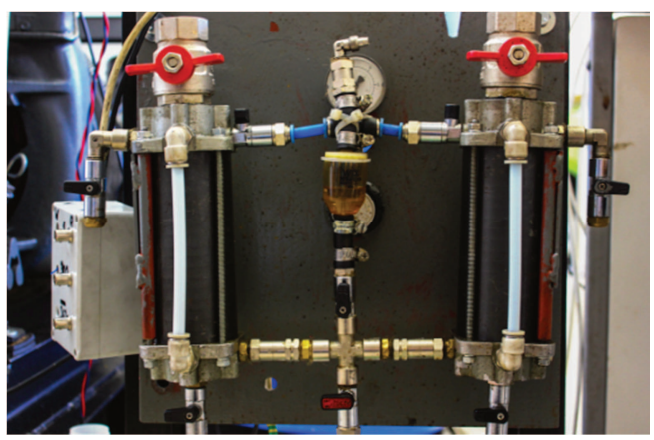

Fig. 1. Dual fuel supply system

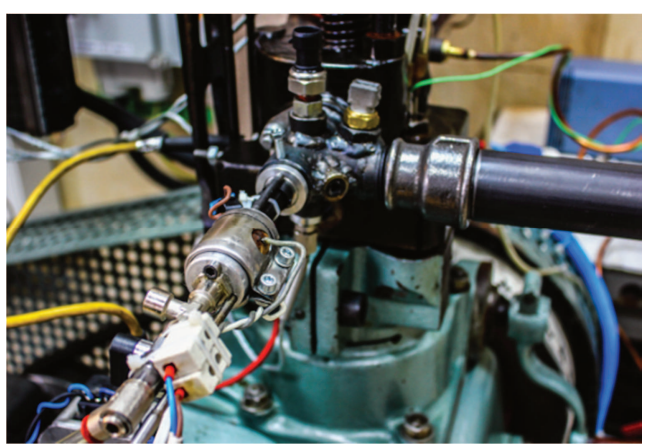

Fig. 2. Heating and fuel injection system

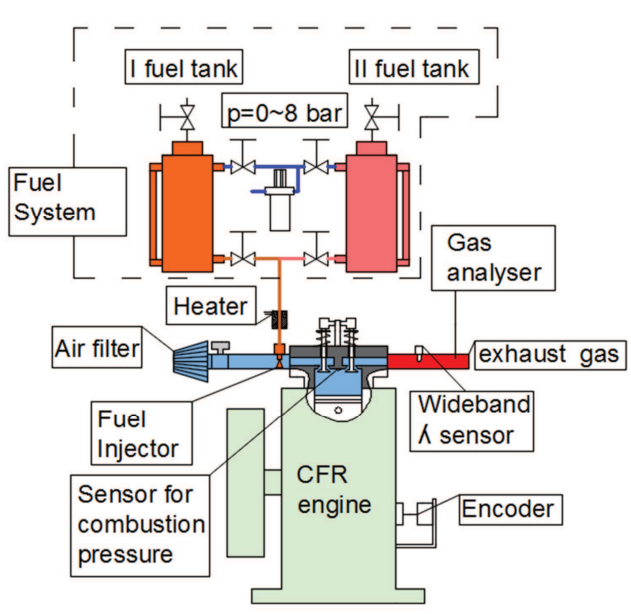

Fig. 3. Scheme of research test stand

\section{Analysis of results}

Tests were conducted to obtain the data as follows:

- In-cylinder pressure,

- Fuel and air temperature,

- Crank angle,

- Lambda ratio,

- THC, $\mathrm{CO}, \mathrm{NO}_{\mathrm{x}}$ emissions.

After data processing the following parameters were determined:

- Indicated mean effective pressure (IMEP) shown in Figure 4,

- $\mathrm{NO}_{\mathrm{x}}$, THC and $\mathrm{CO}$ from exhaust gases depicted in Figures 5,6 and 7, respectively,

- Combustion pressure (Fig. 8, 9) and its derivative over crank angle dp/dCA (Fig. 10),

- Pressure vs. volume plotted in Fig. 11.

As presented in Figure 4, the IMEP for pure butanol is approximately $20 \%$ higher when compared to butanol and $20 \%$ bio-oil blends. However, the IMEP for bio-oil blended butanol the characteristics is flat, hence this is less sensitive to spark timing.

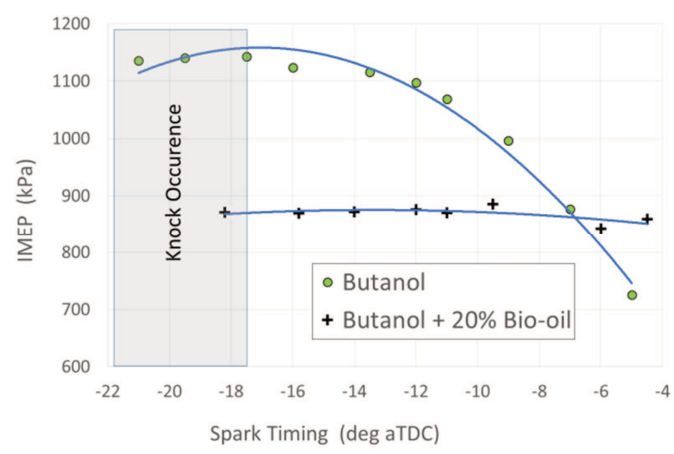

Fig. 4. Indicated mean effective pressure vs. spark timing

Concerning the toxic emissions, it is found that $\mathrm{NO}_{\mathrm{x}}$ emission has its maximum at spark timing in the range from -12 to -6 CA deg after TDC. Total unburned hydrocarbons are at their minimum for spark timings from -16 to $-10 \mathrm{CA}$ deg aTDC. $\mathrm{CO}$ emission is low at spark timing from -12 to -6 CA deg aTDC. This is at the same spark timing range in which the $\mathrm{NO}_{\mathrm{x}}$ is high. Thus, as seen in Figures 5-7 the exhaust emissions for $\mathrm{THC}, \mathrm{CO}$ and $\mathrm{NO}_{\mathrm{x}}$ characterizes with 
trends typical for other common fuels used in the SI engine as eg. gasoline. However, THC look different what might be caused by several poly-aromatic hydrocarbons species diluted in water in the bio-oil. Thus, for their thermal dissociation longer time is required, that can be achieved by ignition discharge more advanced.

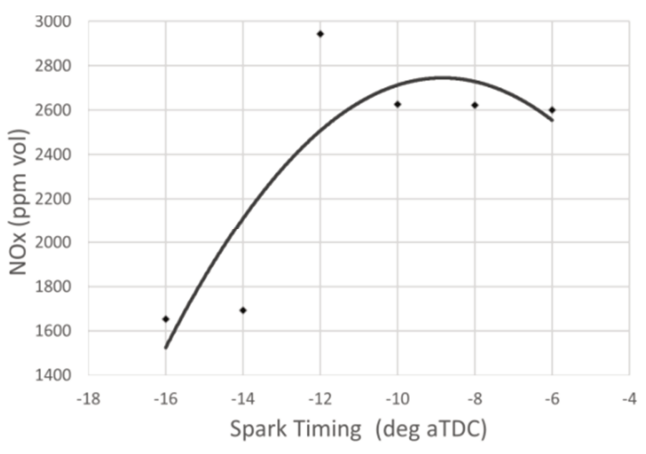

Fig. 5. $\mathrm{NO}_{\mathrm{x}}$ emission as a function of the spark timing

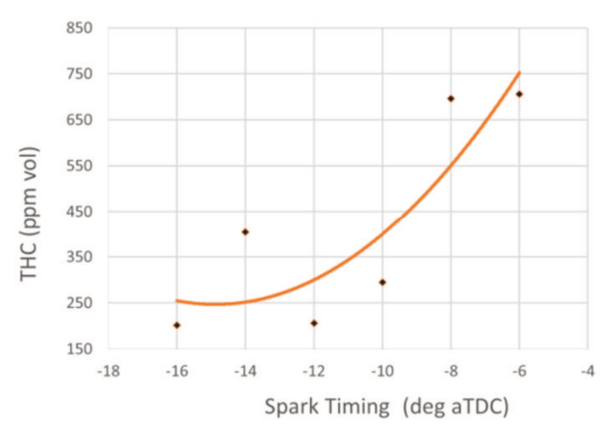

Fig. 6. THC emission as a function of the spark timing

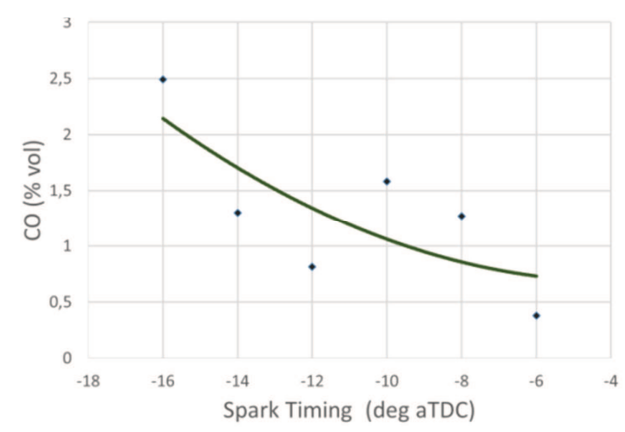

Fig. 7. CO emission as a function of the spark timing

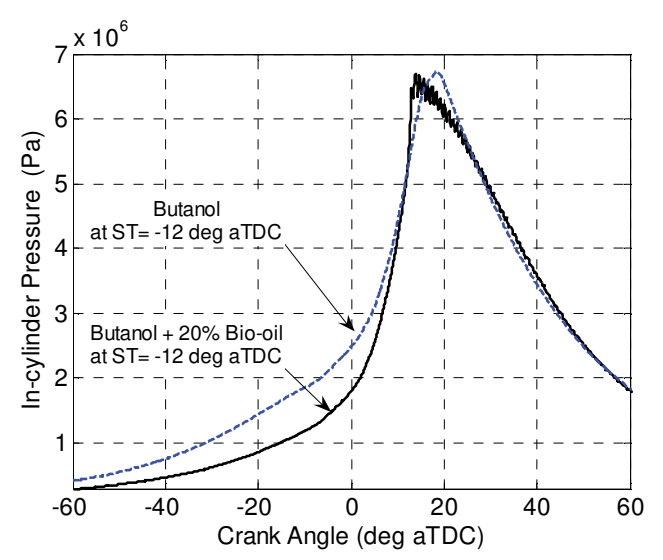

Fig. 8. In-cylinder pressure vs. crank angle
When butanol was blended bio-oil in $20 \%$, anyone can observe tremendous increase in combustion pressure rate as presented in Figure 8 and after filtering in Figure 10. Figure 9 shows closer look on pulsations generated at the end of combustion. They resulted mainly from this high pressure rate observed at the main combustion phase.

As shown in Figure 8 and in Figure 9, pressure pulsations accompany the combustion event of butanol-biooil. The pressure pulsations are characterized with peak-topeak of $400 \mathrm{kPa}$. Such intensity for pulsations can be considered as harmful to the engine [7].

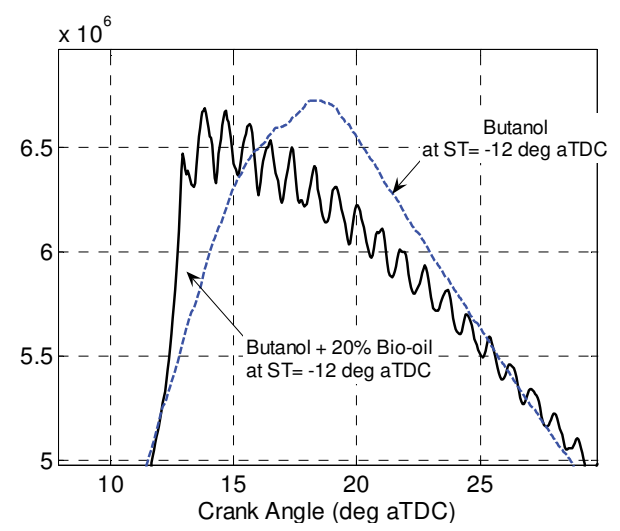

Fig. 9. Zoom on in-cylinder pressure vs. crank angle

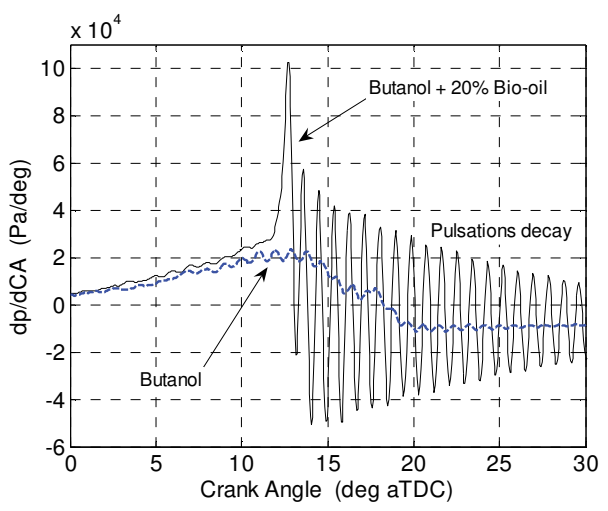

Fig. 10. Pressure rise rate in the function of the crank angle

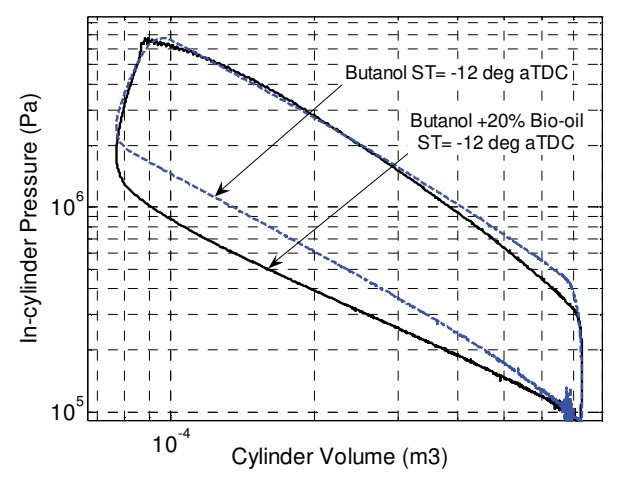

Fig. 11. In-cylinder pressure profile as a function of the cylinder volume

As presented in both Figures 8 and 11, one can conclude that to reduce pressure pulsations and reduce in this way knock intensity, the engine fueled with 
butanol blended bio-oil had to work at lower load by approximately of $20 \%$. Hence, the throttle was closed to the required position to maintain the specific engine load.

\section{Conclusion}

The following conclusions can be drawn from the research:

- Bio-oil can be combusted in the IC engine after its dilution in alcohol eg. n-butanol.

- Due to lower heating value if compared to other fuels the bio-oil in blends decreases overall heating value, so does engine performance.
- Bio-oil as additive to other fuels increases combustion rate, what can cause several symptoms of combustion knock, hence knock reduction measures are required to be implemented in this purpose.

- As far as toxic emission is concerned, addition of $20 \%$ bio-oil to butanol fuel reports similar emission as is typical for other fossil based fuels.

\section{Acknowledgments}

The present research was conducted in the frame of the project No. BIOSTRATEG1/270745/2/NCBR/2015, entitled: "Dietary, Power and Economic Potential of Sida Hermaphrodita Cultivation on Fallow Land" supported by the Polish National Centre for Research and Development.

\section{Nomenclature}

CA crank angle

CI compression ignition

CNG compressed natural gas

DI direct injection
IC internal combustion

IMEP indicated mean effective pressure

LPG liquified petrolum gas

SI spark ignition

\section{Bibliography}

[1] ABOAGYE, D., BANADDA, N., KIGGUNDU, N., KABENGE I. Assessment of orange peel waste availability in Ghana and potential bio-oil yeld using fast pyro-lysis. Renewable and Sustainable Energy Reviews. 70, 2017, 814-821.

[2] BENEROSO, D., MONTI, T., KOSTAS, E.T., ROBINSOS J. Microwave pyrolysis of biomass for bio-oil production: Scalable processing concepts. Chemical Engineering Journal. 2017, 316, 481-498.

[3] GRAB-ROGALINSKI, K., SZWAJA, S. The combustion properties analysis of various liquid fuels based on crude oil and renewables. IOP Conference Series: Materials Science and Engineering. 148(1), 012066.

[4] HASSAN, H., LIM, J.K., HAMEED, B.H. Recent progress on biomass co-pyrolysis conversion into high-quality biooil. Bioresource Technology. 2016, 221, 645-655.

[5] KALARGARIS, I., TIAN, G., GU, S. Combustion, performance and emission analysis of a DI diesel engine using plastic pyrolysis oil. Fuel Processing Technology. 2017, 157, 108-115.

[6] KRUTOF, A., HAWBOLDT, K. Blends of pyrolysis oil, petroleum, and other bio-based fuels: a review. Renewable and Sustainable Energy Reviews. 2016, 59, 406-419.

[7] SZWAJA, S., NABER, J.D. Dual nature of hydrogen combustion knock. International Journal of Hydrogen Energy. 2013, 38(28), 12489-12496.

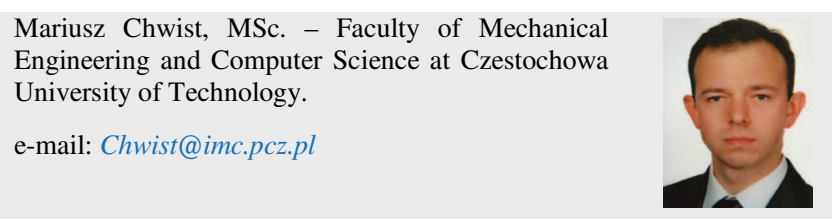

Karol Grab-Rogaliński, MSc. - Faculty of Mechanical Engineering and Computer Science at Czestochowa University of Technology.

e-mail: Grab@imc.pcz.pl

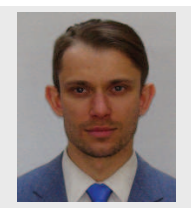

[8] TANSY, WIGLEY, ALEX, C.K., YIP SHUSHENG, PANG. A detailed product analysis of bio-oil from fast pyrolysis of demineralised and torrefied biomass. Journal of Analytical and Applied Pyrolysis. 2017, 123, 194-203.

[9] TUTAK, W., JAMROZIK, A., PYRC, M. Experimental investigations on combustion, performance and emissions characteristics of compression ignition engine powered by B100/ethanol blend. Energy and Fuels. 2016, E3S Web of Conferences 14, 02019.

[10] TUTAK, W., JAMROZIK, A., PYRC, M. Co-combustion of biodiesel with oxygenated fuels in direct injection diesel engine. Energy and Fuels. 2016, E3S Web of Conferences 14, 02018.

[11] TUTAK, W., SZWAJA, S. The effect of methanol-diesel combustion on performance and emissions of a direct injection diesel engine. Journal of KONES Powertrain and Transport. 2015, 22(2), 259-266.

[12] VIHAR, BASKOWIĆ U.Z., SELJAK, T., KATRAŚNIK, T. Combustion and emission formation phenomena of tire pyrolysis oil in a common rail diesel engine. Energy Conversion and Management. 2017.

[13] YONGSHENG, FAN, YIXI CAI, XIAOHUA, LI LIHUA, JIAO JISHENG, XIA XIULI DENG. Effects of the cellulose, xylan and lignin constituents on biomass pyrolysis characteristics and bio-oil composition using the Simplex Lattice, Mixture Design Method Energy Conversion and Management. 2017, 138, 106-118.

Stanisław Szwaja, DSc., DEng. - Faculty of Mechanical Engineering and Computer Science at Częstochowa University of Technology.

e-mail:Szwaja@imc.pcz.pl

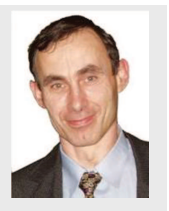

Michał Pyrc, MSc. - Faculty of Mechanical Engineering and Computer Science at Czestochowa University of Technology.

e-mail:Pyrc@imc.pcz.pl

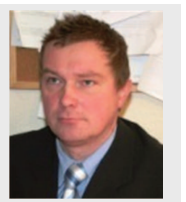

